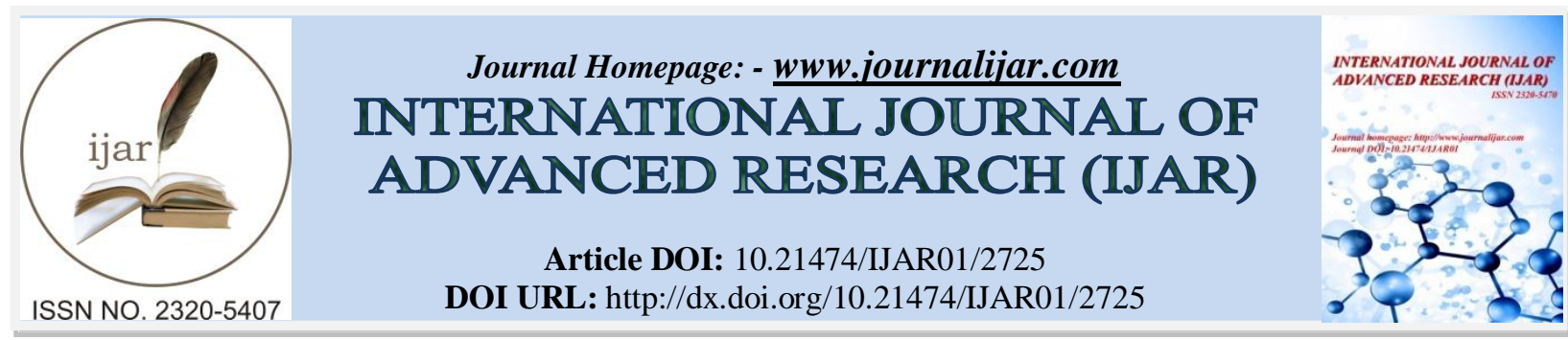

RESEARCH ARTICLE

\title{
DISABILITY IN BANK OFFICE WORKERS DUE TO CERVICOGENIC HEADACHE.
}

\author{
Gaurai Gharote ${ }^{1}$, Raaequa Awati ${ }^{2 *}$, Ujwal Yeole ${ }^{3}$, Rasika Panse ${ }^{4}$, Shweta Kulkarni ${ }^{4}$ and Pournima Pawar ${ }^{4}$. \\ 1. Assistant professor, Tilak Maharashtra Vidyapeeth, Pune. \\ 2. Presenter, final yr.student, Tilak Maharashtra Vidyapeeth, Pune. \\ 3. Principal, Tilak Maharashtra Vidyapeeth, Pune. \\ 4. Assistant professor, Tilak Maharashtra Vidyapeeth, Pune.
}

\section{Manuscript Info}

\section{Manuscript History}

Received: 15 November 2016

Final Accepted: 17 December 2016

Published: January 2017

Key words:-

cervicogenic headache, neck pain, bank office workers.

\section{Abstract}

Background:Headache affects $80-90 \%$ of the population.

Approximately $47 \%$ of the global population suffers from a headache, and 15-20 percent of those headaches are cervicogenic headache Epidemiological researchers suggest prevalence of cervicogenic headache in office workers with neck pain. Cervicogenic headache are usually on one side of the head but can occur on both sides. The pain tends to be dull; not throbbing and can become moderate to severe in intensity. The pain is usually caused by awkward or sustained neck positions and can usually be reproduced by applying pressure to the back of the head and neck.

Aim and objective: To find the incidence of cervicogenic headache in bank office workers.

Methodology: Nationalize bank were downloaded maximum banks were selected. Total 500 subjects were evaluated then concern form was signed and they were assisted for cervical flexion rotation test and Neck disability index.

Results: Mean age ( \pm 40.98$) 20 \%$ had cervicogenic headache with neck pain in bank office worker Neck disability index is as follow Mild $=405$, moderate $=15$, no disability $=80$

Conclusion: $20 \%$ cervicogenic headache in bank office workers.

Copy Right, IJAR, 2016,. All rights reserved.

\section{Introduction:-}

Chronic headache is a significant medical and socioeconomic problem resulting in severe disability and impairment. The term "cervicogenic headache" was coined by Sjaastad in 1983, who also proposed criteria for its diagnosis. Cervicogenic headache as described by Sjaastad et al is characterized as recurrent, long lasting, severe unilateral headache arising from the neck.

Exact pathoanatomic and pathophysiologic basis for cervicogenic headache is unclear. Numerous authors have proposed various theories ranging from neurophysiologic basis involving ascending fibers from the $\mathrm{C} 1$ and $\mathrm{C} 2$ nerve roots to multiple pain generators in pain-sensitive structures involved in head movement.

Headache affects $80-90 \%$ of the population. Cervicogenic headache (CEH) is a symptomatic headache characterized by chronic unilateral headache and symptoms and signs of neck involvement(1,2) CEH is often 
worsened by neck movement, sustained awkward head position or external pressure over the upper cervical or occipital region on the symptomatic side $(1,2)$.Cervicogenic headache $(\mathrm{CGH})$ is a challenging complaint that is commonly faced by physiotherapists in clinical practice. The International Headache Society (IHS) placed cervicogenic headache in the secondary headache sub-group. The global prevalence of headache is about $47 \%$, whereas $15 \%$ to $20 \%$ of those are CGH. Females are four times more prone to CGH than males (3).Persons with chronic CGH experience significant restriction of everyday function and are limited to social involvement, and emotional sufferings. Beside this, the poorer quality of life is seen in these individuals than normal. $(4,5)$ The IHS defines cervicogenic headache $(\mathrm{CGH})$ as "pain, referred from a source in the neck and perceived in one or more Regions of the head and/or face." It is often exaggerated by neck movement, constant uncomfortable head position or external force over the occipital region or upper cervical on the painful side. Headache may arise from various structures of the cervical spine, containing the zygapophyseal joints (occiput-C1, C2, C3).(5,6) Key features of CGH usually are unilateral headache without side-shift combined with neck pain and decreased movement.(6) Up to about $70 \%$ of frequent intermittent headache are reported with associated neck pain making CGH difficult to diagnose. The C1-C2 segment is considered essential to be examined in CGH diagnosis. The relative importance of C1-C2 as a prime cause of CGH has been well established. The cervical flexion-rotation test (FRT) is used to assist in the diagnosis of CGH and, in particular, C1-C2 segmental dysfunction. This manual test involves moving head to fully flexed position, so that spinal movement is ideally controlled to $\mathrm{C} 1-\mathrm{C} 2$, then measuring cervical rotation in this position. Normal range of movement is $44^{\circ}$ to each side. Hall and Robinson have found that subjects with CGH are seemed to have about $17^{\circ}$ less rotation toward the pain side in the FRT, as compare to those with no head pain or migraine with aura. FRT has $91 \%$ sensitivity and $90 \%$ specificity for diagnosis of CGH (7)

The co-occurrence of headache has been found to be 4 times higher in individuals with musculoskeletal symptoms than in those without. In particular, individuals with neck pain have been found to experience headaches more frequently than those with symptoms in other areas. This classification system is mainly based on scientific diagnosis that requires the cervical nociceptive source to be identified via a confirmatory diagnostic block and the headache to have resolved after treatment. In contrast, the diagnostic methods described by the Cervicogenic Headache International Study Group (CHISG) $(8,9)$ are more practical and involve identifying important clinical markers specific for this type of headache. According to the CHISG, the most characteristic aspects of CEH are: 1) unilateral and radiating pain that often starts in the neck or the occipitonuchal area and spreads to the oculo-frontotemporal region 2) temporal pattern of pain that is often continuous but fluctuates in intensity 3) pain induced by improper neck postures or external pressure to the structures in the neck and the occipital region. Neuralgias, such as the greater, lesser, or third occipital neuralgias, affect similar regions at the back of the head. In contrast to patients with CEH, those with neuralgia often use terms such as "stabbing," "jabbing," or "shooting" to describe the pain intensity. In addition, neuralgias do not typically present with associated facial or trigeminal-referred pain. The reason for this observation is that the purported mechanism underlying the development and progression of CEH is the convergence of sensory in puts at the trigeminocervical nucleus. $(9,10)$ A connection between the trigeminal and cervical nerves was postulated in the late 1940s(11), but it was only in 1961 that Frederick Kerr hypothesized a pathogenetic model for head- ache stemming from the cervical region and the posterior fossa.(12) The trigeminal spinal nucleus comprises a rostral sub nucleus oralis, a middle sub nucleus interpolaris and a caudal sub nucleus caudalis(13). The pars caudalis of the spinal tract nucleus of the trigeminal nerve is continuous with the grey matter of the dorsal horns of the spinal cord (14). The spinal terminals of the small sensory fibers enter the cord from the lateral part of the entry zone and have collateral branches that may ascend or descend for up to 3 segments, in the Lissauer's tract, before synapsing in the dorsal horn laminae $(15,16)$. Therefore, along with the 3 upper segments, the middle and lower part of the neck may also be involved in the development of CEH $(17,18)$. These changes in neural connectivity are also evident in the findings of neurophysiological tests. The eye blink reflex (BR) is mediated via the afferent fibers to the trigeminal sensory nuclear complex and their central connections in the trigeminal nucleus. The R1 and R2 components of the BR are mediated via the tactile A $\beta$ afferent fibres. The R3 components are mediated via the thinly myelinated A $\delta$ fibers. Sand et al. (19) compared the BR in patients with $\mathrm{CEH}$, tension-type headache, and migraine with that in the controls. The initial study showed that shorter R1 latencies were found on the symptomatic side than on the asymptomatic side in patients with CEH. In a later study, they reported that stimulation of the symptomatic side in patients with CEH showed a decrease in the R2 duration and the amplitude of the R2 component. These findings point to an associated brainstem hyperactivity (20, 21), possibly involving the ipsilateral trigeminal nucleus. The findings of the quantitative sensory testing (QST) of trigeminal hypersensitivity were consistent with those of the above-mentioned neurophysiological study. La Touche et al. (22) have reported that, compared to the pain-free controls, patients with chronic neck pain showed sensitivity to bilateral mechanical pain over the face. In these patients, pressure hyperalgesia was found over both the masseters 
and temporalis muscles, but not over the tibialis anterior muscle (reference area). However, Chua et al (23).have shown that, compared to chronic neck pain patients without $\mathrm{CEH}$, those with $\mathrm{CEH}$ showed lateralization of pressure hyperalgesia accompanied by thermal hyperesthesia on the painful side of the face. Their suggestion of a rostral neuraxial spread of central sensitization, probably to the ipsilateral trigeminal spinal nucleus, is consistent with Kerr's (6) hypothesis Understanding the mechanisms underlying the development of CEH is the first step toward providing these patients with a better treatment outcome. This understanding will help rationalize the proposed mechanistic approaches that target central sensitization, ablative therapies that focus on primary nociceptive sources, and physical therapies that help relieve pain in secondary areas.

\section{Need of study:-}

Headache affects $80-90 \%$ of the population.

Approximately $47 \%$ of the global population suffers from a headache, and 15-20 percent of those headaches are cervicogenic. Epidemiological researchers suggest a higher prevalence of headache in adults with neck pain. Bank office workers mainly sit in erect posture and work continuosly on computer sothere is high chances of cervicogenic headache inthem. Therefore the purpose is to study the incidence of cervicogenic headache in bank office workers.

\section{Aim and objectives:-}

To find the incidence of cervicogenic headache in bank office workers.

\section{Hypothesis:}

Null:- There is no incidence of cervicogenic headache in office workers.

Alternative:- There is prevalence of cervicogenic headache in office workers.

Materials and Methodology:-

Study design:- Survey Study setting: nationalize banks.

Target population: office workers in banks.

Sample size:500

1. Inclusion criteria: bank office-worker, constant or frequently occurring neck pain.

2. Exclusion criteria: specific disorders of the cervical spine, instability.

3. List of nationalised banks around Pune were made.

4. Banks with more than 200 workers were considered and visited.

Sampling: 500 subjects were selected having headache and neck pain irrespective of their gender, age, and working period.

\section{Questionnaire:-}

All persons received a questionnaire with a standard letter containing information about the project. Apart from ensuring confidentiality and emphasizing the importance of participation, it was stated that the object was to study the cervicogenic headache.

\section{Cervical flexion rotation test:-}

During the Cervical Flexion Rotation Test (CFR), the patient is supine and the examiner flexes the cervical spine fully in order to block rotational movement below the atlanto axial articulation. The examiner then passively rotates the head left and right, determining range of motion (ROM) and end-feel. A firm end-feel with limited ROM presumes limited rotation of the atlas on the axis.

The CFR has been shown to have an overall diagnostic accuracy of $85-91 \%$.

\section{Results:-}

\begin{tabular}{|c|c|}
\hline Ages & No. of people \\
\hline 21 to 30 & 98 \\
\hline 31 to 40 & 189 \\
\hline 41 to 50 & 111 \\
\hline
\end{tabular}




\begin{tabular}{|c|c|}
\hline 51 to 60 & 102 \\
\hline total & 500 \\
\hline
\end{tabular}

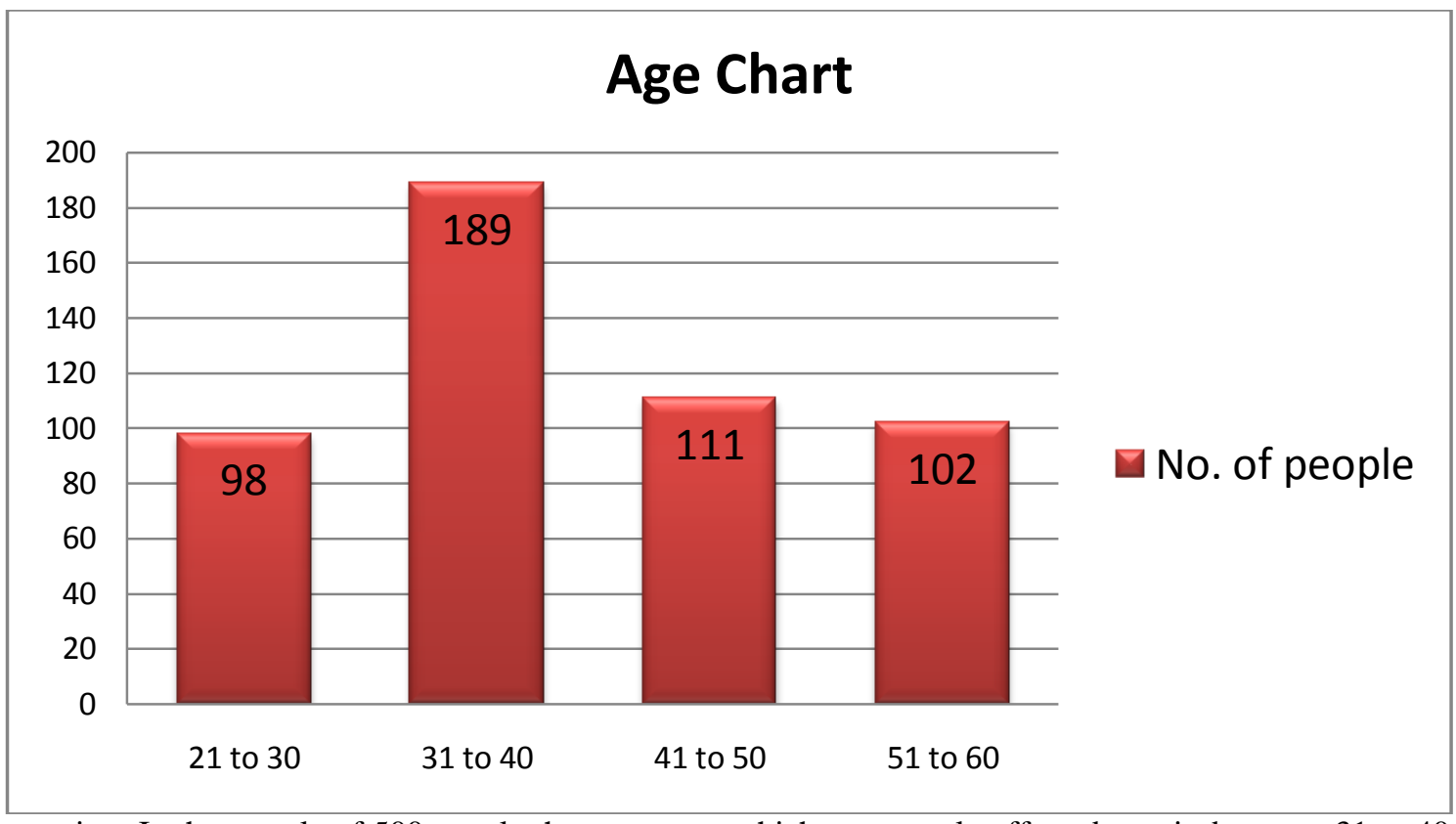

Interpretation: In the sample of 500 people the age group which was mostly affected was in between 31 to 40 (189 peoples) after that 41 to 50(111 peoples); 51 to 60(102 peoples) and are less in age group 21 to 30(98 peoples)

\begin{tabular}{|c|c|}
\hline Mild & 291 \\
\hline Moderate & 6 \\
\hline No Disability & 53 \\
\hline
\end{tabular}

\section{Neck Disability Index}

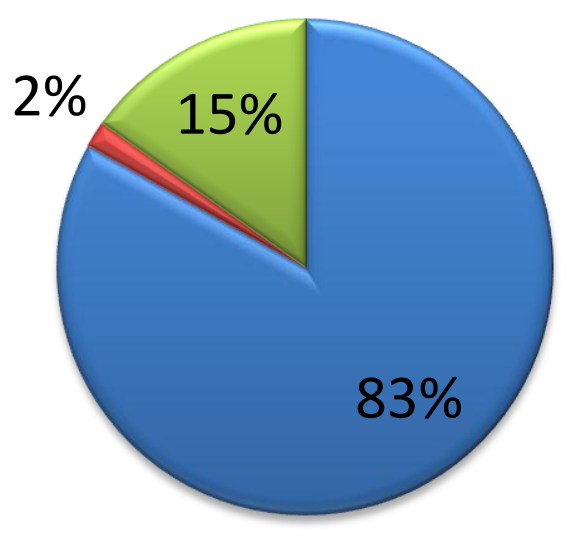

Mild

Moderate

No Disability

Interpretation:- In a sample of 500peoples, 291 peoples have mild (81\%); 06 peoples have moderate (3\%); 53 peoples have no disability (16\%)

\begin{tabular}{|l|l|}
\hline Positive & Negative \\
\hline 100 & 400 \\
\hline
\end{tabular}




\section{Cervical Flexion Rotation Test}

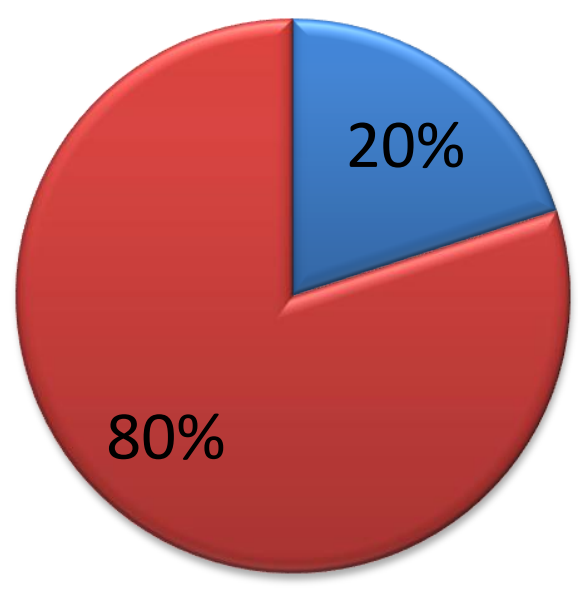

positive negative

Interpretation: In sample of 500 people the cervical flexion rotation test was positive in 100 peoples (20\%); and negative in 400peoples $(80 \%)$

\section{Discussion:-}

Cervicogenic headache is a complex syndrome caused by a variety of lesions that might reproduce pain on the contralateral side (24). Patients with bilateral headache or neck pain after whiplash injury are diagnosed as cervicogenic headache in many headache centers. It is also difficult to be absolutely sure of how strictly the criterion of unilaterality has been followed in other epidemiological studies. The majority of headache days were characterized by a unilateral moderate/severe pressing/ tightening pain without accompanying symptoms.

\section{A study says that cervicogenic headache may occur because of:-}

Bad sitting posture, Prolonged periods of sitting or static postures in general, Having an inappropriate workstation, Getting overtired to the point of exhaustion.

As the bank office workers have mainly all of the above conditions so the study was done on them.

Typically, the headache: is recurrent, long-lasting and severe.Arises from the neck . has a unilateral dominance (but can bilateral). is in the low occipital and temporal region (with possible radiation in the face, per orbital, frontal and parietal region and ipsilateral shoulder and arm).Is accompanied with a reduced cervical spine range of motion.Can be precipitated with certain neck motions.

Considering that Cervicogenic headache is a daily chronic pain, surprisingly only $2 \%$ had consulted a neurologist and only $10 \%$ had consulted a pain clinic. This may be due to moderate pain intensity. The lack of consulting a headache specialist may also contribute to medication overuse.

This study is the first to investigate the incidence of cervicogenic headache in bank office workers.

Determining the etiology of cervicogenic headaches is often frustrating for both the patient and physician. Differentiating between cervicogenic headache and other forms of headache is difficult because not only is there variability in headache presentation, but there is also considerable symptom overlap. Many authors have suggested varying methods to diagnose and differentiate cervicogenic headache from other various forms of headaches. Use of clinical criteria has been strongly advocated $(25,26,27)$. Significant variations in the definition of cervicogenic headache among clinicians have clouded not only the incidence and prevalence of cervicogenic headache, but also its treatment recommendations and outcomes (28). 
All the patients in this study were between the age group of 20-60 years.

Cervicogenic headache has an involved biomechanical and neural mechanism with cervical association, which makes the task of studying cervicogenic headache challenging.

In order to grasp the concept of cervicogenic headache, it is important to understand the background. We naturally started our search for such cases among patients in whom headache was the main complaint. We more or less had to start our search from scratch, and when one does not know what one is searching for, the search is going to be characterised by trial and error. A decisive feature in identifying the first case around 1980 was the mechanical precipitation mechanism. Once the first case was identified, other cases followed suit.

Criteria for cervicogenic headache.Unilaterality without sideshift, Pain triggered by neck movement and/or sustained awkward position,Pain elicited by external pressure over the ipsilateral upper, posterior neck region or occipital region, Ipsilateral non-radicular neck, shoulder, and arm pain, Reduced range of motion in the cervical spine,Non-clustering pain episodes ,Pain episodes of varying duration or fluctuating, continuous pain,Moderate, non-excruciating pain, usually of a non-throbbing nature,Pain starting in the neck, eventually spreading to oculofronto-temporal areas where the maximum pain is usually located, Anaesthetic blockades of the major occipital nerve; $\mathrm{C} 2$ root or other appropriate structures on the symptomatic side abolish the pain transiently, provided anaesthesia is obtained,Female sex, Head and/or neck trauma, Nausea,Vomiting,Ipsilateral edema, and - less frequently - flushing, mostly in the periocular area , Dizziness,Phono- and photophobia , Ipsilateral "blurred vision", Difficulties on swallowing

The available studies that can tell something useful about the incidence of Cervicogenic headache can be divided into two groups: (i) regular hospital/outpatient series that compare the incidence of Cervicogenic headache with the incidence of, for example, migraine and tension headache; and (ii) population studies.

Maciel et al. (29) found a 15\% frequency of CEH in a headache clinic series $(n=1,229)$. This frequency is probably far above what can be expected for e.g. cluster headache. Their view that CEH is one of the three major headaches may be defendable.

In Vincent \& Luna's series (30), there were $33 \mathrm{CEH}$ patients, 29 episodic tension headache patients, and 65 common migraine patients.

It is remarkable that in two studies both claiming to have used the IHS criteria $(31,32)$, one (32) found 44 times as many cases of $\mathrm{CEH}$ as the other (31).This indicates that the time is ripe for an appreciable upgrading of the IHS criteria $(30,31)$. In addition, proper population studies with proper criteria must be carried out as regards CEH.

The purpose of study was to find out the incidence of cervicogenic headache in bank office workers. The cervicogenic headache is mostly neglected or left untreated. The bank office workers population was considered for study as they work continuosly on computers and have chances of occurring musculoskeletal problems and cervicogenic headache. The aim was to find out the percentage of cervicogenic headache in bank office workers. The study was conducted as survey method. Study was done at various banks around pune city. The data were collected by questionnaire method and cervicalflexion rotation test. The Target population was office workers in banks. Samples that have specific disorders of the cervical spine, instability were excluded.In this study the 500 samples were selected based on the inclusion and exclusion criteria. The exculsion criteria was specific disorders of the cervical spine, instability etc. The inculsion criteria considered was bank office-worker, constant or frequently occurring neck pain.

The samples were included in the bases of their willingness of self-participation individually. The investigations were done on the bases of validated scales.

Results show that there is $20 \%$ of incidence of cervicogenic headache in bank office workers.

\section{Conclusion:-}

In our study 500 bank office workers were assisted for CGH by doing cervical flexion rotation test and neck disability index questionnaire from which we found that 100 peoples were having positive cervical flexion rotation 
test with neck disability index in which 291 persons had mild pain,06 persons have moderate pain and 53 persons had no neck disability.

Therefore there is $20 \%$ of incidence in bank office workers.

\section{Limitation and scope:- \\ Limitations:-}

Duration of working hours were not considered,Argonomic conditions were not included, Years of working were not considered, Posture analysis was not done.

\section{Scope:-}

Can be done in particular age group.Can be done in any particular gender.Can be done in various types of office workers.

\section{Referances:-}

1. Sjaastad O, Fredriksen TA, Pfaffenrath V. Cervicogenic headache: diagnostic criteria. The Cervicogenic Headache International Study Group. Headache 1998; 38: 442-445.

2. International Headache Society. The International Clas- sification of Headache Disorders. 2nd ed. Cephalalgia 2004; 24: 1-160.

3. Umar M, Naeem A, Badshah M, Zaidi S. A randomized control trial to review the effectiveness of cervical mobilization combined with stretching exercises in cervicogenic headache. J Public Health Biolo Sci 2012; 1(1): 09-13

4. 4.Page P. Clinical suggestion cervicogenic headaches: an evidence based approach to clinical management. Int $\mathrm{J}$ Sports Phys Ther 2011; 6 (3): 254-66.

5. Hall T, Briffa K, Hopper D. Clinical Evaluation of Cervicogenic Headache: A Clinical Perspective. J Man Manip Ther 2008; 16(2): 73-8

6. Penzien DB, Andrasik F, Freidenberg BM, Houle TT, Lake AE 3rd, Lipchik GL, et al. Guidelines for Trials of Behavioral Treatments for Recurrent Headache, First Edition: American Headache Society Behavioral Clinical Trials Workgroup. Headache 2005; 45(2): 110-32. http://dx.doi.org/10.1111/j.1526-4610.2005.4502004.x

7. Hall T, Briffa K, Hopper D, Robinson K. Long-Term Stability and Minimal Detectable Change of the Cervical Flexion- Rotation Test. J Orthop Sports Phys Ther 2010; 40(4): 225-9. http://dx.doi.org/10.2519/jospt.2010.3100

8. Sjaastad O, Fredriksen TA, Pfaffenrath V. Cervicogenic headache: diagnostic criteria. The Cervicogenic Headache International Study Group. Headache. 1998;38(6):442-5.

9. Evers S. Comparison of cervicogenic headache with migraine. Cephalalgia. 2008;28(Suppl 1):16-7.

10. Bogduk N, Govind J. Cervicogenic headache: an assessment of the evidence on clinical diagnosis, invasive tests, and treatment. Lancet Neurol. 2009;8(10):959-68.

11. Escolar J. The afferent connections of the 1st, 2nd, and 3rd cervi- cal nerves in the cat; an analysis by Marchi and Rasdolsky meth- ods. J Comp Neurol. 1948;89(2):79-92.

12. Kerr FW. Structural relation of the trigeminal spinal tract to up- per cervical roots and the solitary nucleus in the cat. Exp Neurol. 1961;4:134-48.

13. Olszewski J. On the anatomical and functional organization of the spinal trigeminal nucleus. J Comp Neurol. 1950;92(3):401-13.

14. Bogduk N. The anatomical basis for cervicogenic headache. J Ma- nipulative Physiol Ther. 1992;15(1):67-70.

15. Kerr FW. Central relationships of trigeminal and cervical primary afferents in the spinal cord and medulla. Brain Res. 1972;43(2):561-72.

16. Siddall PJ, Cousins MJ. Pain mechanisms and management: an update. Clin Exp Pharmacol Physiol. 1995;22(10):679-88.

17. Michler RP, Bovim G, Sjaastad O. Disorders in the lower cervical spine. A cause of unilateral headache? A case report. Headache. 1991;31(8):550-1.

18. Fredriksen TA, Salvesen R, Stolt-Nielsen A, Sjaastad O. Cervico- genic headache: long-term postoperative follow-up. Cephalalgia. 1999;19(10):897-900.

19. Sand T, Zwart JA. The blink reflex in chronic tension-type headache, migraine, and cervicogenic headache. Cephalalgia. 1994;14(6):447-50; discussion 394-5.

20. Frese A, Evers S. Biological markers of cervicogenic headache. Cephalalgia. 2008;28(Suppl 1):21-3.

21. Sand T, Moll-Nilsen B, Zwart JA. Blink reflex R2 amplitudes in cervicogenic headache, chronic tension-type headache and mi- graine. Cephalalgia. 2006;26(10):1186-91. 
22. La Touche R, Fernandez-de-Las-Penas C, Fernandez-Carnero J, Diaz-Parreno S, Paris-Alemany A, ArendtNielsen L. Bilateral me- chanical-pain sensitivity over the trigeminal region in patients with chronic mechanical neck pain. J Pain. 2010;11(3):256-63.

23. Chua NH, van Suijlekom HA, Vissers KC, Arendt-Nielsen L, Wild- er-Smith OH. Differences in sensory processing between chronic cervical zygapophysial joint pain patients with and without cer- vicogenic headache. Cephalalgia. 2011;31(8):953-63

24. Antonaci F, Bono G, Chimento P. Diagnosing cervico- genic headache. [Review]. J Headache Pain 2006; 7: $145-148$.

25. Sjaastad O, Saunte C, Hovdahl H et al. "Cervicogenic" headache. An hypothesis. Cephalalgia 1983; 3:249256.

26. Sjaastad O, Fredriksen TA. Cervicogenic headache: Criteria, classification and epidemiology. Clin Experiment Rheum 2000; 18(2 Suppl 19): S3-6.

27. Sjaastad O, Fredriksen TA, Pfaffenrath V. Cervicogenic headache: Diagnostic criteria. Headache 1990; 30:725-726.

28. Leone M, D'Amico D, Grazzi L et al. Cervicogenic headache: A critical review of the current diagnostic criteria. Pain 1998; 78:1-5.

29. MACIEL JA JR., CARMO EC, RUOCCO H, et al.: Cefaleia. Estudio clinico de 1229 casos. Arch NevroPsiquiatria 1994; 52: (Suppl) OR-030.

30. VINCENT M, LUNA RA: Cervicogenic head- ache: a comparison with migraine and tension headache. Cephalalgia 1999; 19 (Suppl. 25): 11-16.

31. PEREIRA MONTEIRO J: Cefaleias. Estudo epid- emiologico e clinico de uma populacão urbana. [Thesis] University of Porto (Portugal), 1995.

32. NILSSON N: The prevalence of cervicogenic headache in a random population sample of 20-59 year olds. Spine 1995; 20: 1884-8. 